\title{
Los mocobíes del Chaco según la mirada del P. Manuel Canelas SJ
}

\author{
The mocobíes from Chaco according to
} Manuel Canelas SJ

María Laura Salinas y Fátima V. Valenzuela*

\section{Resumen}

Nos proponemos en este trabajo analizar el documento escrito por el P. Manuel Canelas denominado Origen de la Nación Mocobí y relato de sus usos y costumbres. Dicha fuente refleja el interés de los padres jesuitas por historizar y narrar los aspectos significativos de los pueblos indígenas, en este caso específicamente, mocobíes. Parte del documento fue utilizado y analizado anteriormente por Guillermo Furlong para su obra Entre los Mocobíes de Santa Fe (1938). En esta ocasión nos abocaremos a examinar el manuscrito y dar cuenta de la valiosa información que aporta sobre la etnia mocobí referente a su vida cotidiana, religiosa y a la cosmovisión del mundo.

La fuente tiene la autoría de Manuel Canelas, un jesuita nacido en Córdoba del Tucumán cuya labor misional la realizó en la reducción de San Javier en Santa Fe durante unos diez años, circunstancia que le permitió convertirse en un investigador completo y de gran conocimiento sobre el carácter y las costumbres de esta etnia.

Palabras Claves: Jesuitas-Chaco-Mocobies-Siglo XVIII-reducciones

\begin{abstract}
We propose in this paper to analyze the document Manuel Canelas S.J written .called Origin of the Nation story Mocobí and their customs. This source reflects the interest of the Jesuits by historicizing and narrate significant aspects of indigenous peoples, in this case specifically Mocobies. Part of the document was previously used and analyzed by William Furlong for his work among Mocobies Santa Fe (1938). This time we will
\end{abstract}

\footnotetext{
* IIGHI-Conicet-UNNE.
} 
focus on examining the manuscript and account for the valuable information provided on the ethnic mocobí concerning everyday, religious worldview and life.

The source has authoring Manuel Canelas, a Jesuit born in Cordoba of Tucuman whose missionary work was done in the reduction of San Javier in Santa Fe for about ten years, a fact that enabled him to become a full researcher and knowledgeable about the character and customs of this ethnic group.

Keywords: Jesuits-Chaco-Mocobíes-XVIII century-indigenous towns

Recibido: 20 de diciembre de 2015

Evaluado: 28 de diciembre de 2015 
La Orden jesuítica produjo un copioso material documental en el Nuevo Mundo que fue elaborado, en el marco de una imperiosa necesidad de contar, narrar y relatar sus experiencias misionales. Si bien el interés estaba puesto en la cuestión de la evangelización, desde una perspectiva etnográfica, también caracterizaron a las diferentes etnias con las que establecieron vínculos en el espacio americano ${ }^{1}$.

La importancia de estas fuentes radica en la valiosa información que brindan para la reconstrucción de la historia cultural de los pueblos pre-hispánicos, siendo herramientas de primera mano para los estudios antropológicos y etnohistóricos, entre otros, pues nos acercan una mirada de las poblaciones históricas.

En esta oportunidad, nos proponemos analizar el documento escrito por el P. Manuel Canelas denominado Origen de la Nación Mocobí y relato de sus usos y costumbres. Dicha fuente refleja el interés de los padres jesuitas por historizar y narrar los aspectos significativos de los pueblos indígenas, en este caso específicamente, mocobíes. Parte del documento fue utilizado y analizado anteriormente por Guillermo Furlong para su obra Entre los Mocobíes de Santa Fe (1938). En esta ocasión nos abocaremos a examinar el manuscrito y dar cuenta de la valiosa información que aporta sobre la etnia mocobí referente a su vida cotidiana, religiosa y a la cosmovisión del mundo ${ }^{2}$.

La fuente tiene la autoría de Manuel Canelas, un jesuita nacido en Córdoba del Tucumán cuya labor misional la realizó en la reducción de San Javier ${ }^{3}$ en Santa Fe durante unos diez años, circunstancia que le permitió convertirse en un investigador completo y de gran conocimiento sobre el carácter y las costumbres de los indios mocobíes ${ }^{4}$.

Existen escasos estudios desde la perspectiva histórica y antropológica sobre los mocobí, quienes integraban junto con los tobas, abipones y mbayas el grupo lingüístico de los guaycurúes o formaban parte de una cadena étnica.

Entre los antecedentes se destacan los abordajes de Branislava Susnik, Silvia Citro y Florencia Nesis. Las inve stigaciones de Susnik brindan una mirada global de los pueblos guaycurúes y a su vez, permiten caracterizar a cada grupo étnico: tobas, mocobíes y abipones.

\footnotetext{
${ }^{1}$ Una primera versión de este trabajo se presentó en las XV Jornadas Internacionales sobre las Misiones Jesuiticas. Pontificia Universidad Católica de Chile. Santiago de Chile. Agosto de 2014

${ }^{2}$ Furlong (1955: 87) ubica el documento en el Archivo de la Provincia Tarraconense de San Cugat (Barcelona). En el manuscrito original a foja $\mathrm{n}^{\circ} 9$ hay un sello de goma y tinta en donde se lee Archivo Histórico de la Provincia de Aragón y el ms. esta numerado bajo el $\mathrm{N}^{\circ} 2655$. En el lomo de la encuadernación dice ARX HIST S. I. /Catalunya/AC/MI/02/03 [El 02 esta tachado y el 03 agregado a lápiz] Asimismo en el lomo de dicha encuadernación se conserva el número de MS 2655. Al unificarse recientemente la provincia jesuítica española, los documentos de Barcelona se llevaron a Alcalá de Henares. Véase también Page, 2011: 1-20.

${ }^{3}$ La reducción de San Javier se fundó en el año 1743 como resultado de un extenso proceso de negociaciones. Estas últimas habían comenzado con el diálogo entre el gobernador y el jefe mocobí Ariacaiquin, quien luego fue muerto por los españoles en Córdoba luego de un ataque a dicha ciudad. Según el relato de Paucke su hermano Cithaalín inició nuevamente las negociaciones, decidiendo reducirse. A él lo siguió Aletin y conformaron el poblado un conjunto de doce indios con su parentela. Se organizó la reducción en el sitio en el que había estado emplazada la primera ciudad de Santa Fe (Furlong, 1938: 34 y Page: 2012: 223-341).

${ }^{4}$ Furlong, 1938: 78.
} 
En el caso de Silvia Citro ha focalizado el estudio en las relaciones de liderazgo en tres períodos históricos, el pre-hispánico, el hispánicos y la etapa post-colonial, para lo que recurrió al análisis de los rituales, festividades que le permitieron reconstruir la construcción y legitimación del poder ${ }^{5}$ Los trabajos de Florencia Nesis contextualizan a los grupos mocobí antes de la formación de la reducción de San Javier analizando las formas de asentamientos, territorialidad y movilidad, entre otras temáticas. Su estudio se centra en el período jesuítico durante el siglo XVIII, en el cual se analizan las relaciones que se gestan durante la instalación de la reducción de San Javier.

Nuestro enfoque pretende realizar una exploración historiográfica de la fuente mencionada con el fin de ofrecer un panorama más amplio sobre la mirada de los jesuitas hacia un grupo étnico guaycurú, es decir, encontrar los ejes y aspectos en los que ha centrado sus observaciones Manuel Canelas y presentar el documento, sin la lectura mediadora de Guillermo Furlong, que es quien mayormente ha utilizado y presentado el documento.

\section{Una mirada a las fuentes jesuíticas}

Los padres de la Compañía de Jesús elaboraron un nutrido grupo de obras que abarcaron tanto la crónica eclesiástica como la vida política y social de los distritos americanos, a lo que se agregaron no pocas monografías dedicadas a pueblos indígenas o regiones particulares lo que enriqueció su aporte a la historiografía.

La historiografía actual ha ido caracterizando de diversas formas el variado corpus documental producido por la Compañía de Jesús, uno de esas visiones más críticas ha sostenido que estas fuentes sólo reflejaban "un discurso triunfalista de la labor apostólica de la Iglesia en el Nuevo Mundo"6 enfatizando principalmente la tarea misional y destacando la voluntad de sacrificio del sujeto misionero. Por lo cual, estas fuentes no poseían elementos para el análisis histórico y antropológico pues eran meros instrumentos de propaganda de su tarea evangélica en Europa.

Es evidente que las narraciones jesuitas manifestaron un objetivo claro, no obstante podemos establecer una diferenciación en estas fuentes según el género y el momento en que fueron redactadas. Las fuentes fueron generadas como una comunicación regular entre los pueblos y la Orden en Europa o las primeras crónicas y testimonios $^{7}$, existieron obras que han permitido dar cuenta especificidades de los pueblos amerindios lo que situó a los misioneros como verdaderos "antropólogos avant la lettre" ${ }^{\text {p }}$ pues en sus escritos volcaron las experiencias ya sea como etnologías comparativas o relatos personales de diarios de campos, en las cuales brindaron datos sobre su interacción con las sociedades indígenas.

En algunos casos su mirada privilegió la botánica o zoología sobre la parte etnográfica o antropológica como por ejemplo en la obra de Pedro Lozano, Tomas

\footnotetext{
${ }^{5}$ Citro, 2003: 170

${ }^{6}$ González, 2012: 178.

${ }^{7}$ En este sentido, hacemos una diferenciación entre las Cartas Anuas que eran una correspondencia en forma periódica que se remitía a Europa; y las primeras crónicas como por ejemplo la obra de P. Antonio Ruiz de Montoya de las obras producidas en el siglo XVIII, tras la expulsión que tenían otros fines y brindaban mayores conocimientos.

${ }^{8}$ Wilde, 2014: 4.
} 
Falkner, José Sánchez Labrador, Martín Dobrizhoffer, José de Acosta y José de Gumilla. En sus narrativas se buscaba ante todo "dar a conocer a Europa la novedad del hombre americano en toda su variedad de parcialidades, lenguas y culturas, así como describir la fauna exótica o elaborar un recetario botánico"”.

En tanto, otros misioneros priorizaron la mirada etnográfica centrada en describir exhaustivamente a las poblaciones indígenas y sus modos de vida como los casos de Florián Paucke o Martín Dobrizhoffer, entre otros. Sus análisis incluían retomar aspectos físicos de las parcialidades, sus rituales durante el nacimiento, matrimonio y defunción, lo que convirtió a las obras en verdaderos trabajos de antropología social americana.

No obstante, en la actualidad se discute y debate en forma constante la utilización o no de las fuentes producidas por los misioneros para conocer la realidad indígena. Charlotte de Castelnause se ha preguntado “¿Cómo hacer una antropología y una historia de las poblaciones autóctonas a partir de las fuentes misionales? ¿En qué medida los misioneros comprendieron realmente las culturas indígenas? ¿En qué tipos de textos misioneros encontramos información etnográfica (en los tratados de descripción de costumbres o en las cartas) ¿Podemos hablar de saberes misioneros sobre los indios?" ${ }^{10}$.

En este sentido, sostiene Wilde que se debería diferenciar en el corpus de la historiografía jesuítica del exilio porque fue la que desarrolló un cambio cualitativo de orientación, pues se hizo más científica, en tono con el espíritu de la época, ligado a la necesidad de producir un conocimiento distante, analítico, hasta cierto punto desapasionado, basado en la recolección de datos y la observación empírica, a lo que agregamos, sin la pérdida del sentido apologético que siempre estuvo presente en la escritura jesuítica.

En esta historiografía del exilio podríamos incluir la fuente analizada en esta oportunidad, perteneciente al P. Manuel Canelas denominada “Origen de la Nación Mocobí y relato de sus usos y costumbres”. Esta fue elaborada posteriormente a la expulsión de la Compañía de Jesús de los dominios americanos y su exilio en Europa.

Si tenemos en cuenta el contexto de producción, según la visión de Furlong, deberíamos señalar que fue un encargo realizado por el padre Joaquín Camaño quien tenía el objetivo de realizar "una vasta enciclopedia étnica y solicitó a los misioneros rioplatenses materiales de primer orden que reflejaran sus vivencias, recuerdos, labor y experiencias personales" ${ }^{11}$. De allí surgió lo que se denominó posteriormente Misiones del Chaco. Mártires y Tonkin una obra colectiva en la cual habían numerosas monografías de los misioneros que habían trabajado con los indígenas americanos y fueron desterrados en 1767, entre las que aparecen las relaciones del padre Canelas y Burgés esta última era la "Relación de la fundación del pueblo de San Javier de los Mocobíes". A estos escritos se sumó la monografía del padre Camaño sobre las Naciones del Chaco y la Relación de los indios Tobas y Mocobíes del P. Román Arto. Posteriormente fue encontrada la relación del padre Antonio Bustillo, también referente a los mocobíes.

\footnotetext{
${ }^{9}$ O'Neill-Dominguez, 2001:133.

${ }^{10}$ Wilde, 2014: 5.

${ }^{11}$ Furlong, 1938: 6.
} 
Estas monografías permanecieron inéditas hasta que el padre Guillermo Furlong las dio a conocer a partir de la trascripción en toda su integridad de las obras de Canelas, Burgés y Bustillo en su denominada obra Entre los Mocobíes de Santa Fe ${ }^{12}$ que fue editada en 1938.

Creemos que la obra Entre los Mocobíes de Furlong se articula dentro su producción historiográfica, en la cual ha intentado demostrar una historia de un cristianismo feliz, es decir, cómo la obra de Dios se materializó en las misiones jesuíticas. Estos supuestos se plasmaron de tal forma que Furlong recurrió al corpus documental con un objetivo central, dar cuenta del origen de la reducción de San Javier, relegando y parcializando las temáticas centrales de las narrativas jesuíticas, que en el caso de Canelas no era justamente la fundación de la reducción de San Javier, aunque si en un capítulo menciona la tarea misional no siendo el eje de su relación.

Por otra parte, el análisis pormenorizado de la obra de Furlong nos permitió comprobar que él utilizó algunos de los extractos de las fuentes originales a los cuales fragmentó y hasta incluso, generó una pérdida del sentido global de dicha fuente. Su operación historiográfica fue desarrollar una historia de la reducción de San Javier y los mocobíes, adoptando la práctica de trascribir ciertas partes de los manuscritos originales y hasta incluso hilar su texto a partir de las ideas de diversos misioneros, con lo cual, no siempre se sabía de quien eran esas conclusiones.

Por ese motivo creemos necesario analizar la fuente de Canelas de primera mano, con el objetivo de caracterizar intrínsecamente sus elementos, mirada y percepción que tuvo sobre los mocobíes, dejando en un segundo plano la versión realizada por Furlong que presenta ciertas particularidades que obstaculizan una visión global de lo que consideramos, pretendía Canelas exponer en su relación.

Creemos que esta relación sobre los mocobíes permite dar cuenta de un momento anterior a la llegada de los misioneros, pues rescata prácticas sociales y culturales de la parcialidad y su idiosincrasia.

\section{Manuel Canelas, un jesuita entre mocobíes...}

Manuel Canelas fue un jesuita originario de las tierras americanas, había nacido en Córdoba el 24 de abril de 1718 e ingresado en la Compañía el 3 de marzo de 1739 en la Provincia del Paraguay. Ingresó en el Convictorio de Monserrat en $1734^{13}$ y desde allí concurría a la Universidad en donde estudió tres años de Filosofía y dos de Teología. Decidida su vocación religiosa dio su nombre a la Compañía de Jesús el 3-III1739 y el catálogo de ese año agrega que era maestro en Teología. En cuanto a sus dotes naturales era de buen ingenio, suficiente juicio y corta prudencia, de temperamental carácter y buena disposición para las letras. En 1744 está registrado en los catálogos de

\footnotetext{
${ }^{12}$ De este pueblo guaycurú también tenemos la obra del P. Florián Paucke denominada Hacia allá y para acá, una entrada entre los indios mocobíes, 1749-1767. Esta monumental obra consta de 4 tomos y pertenece a la literatura jesuítica del exilio, ha sido la fuente clásica para los abordajes históricos y antropológicos centrados en el pueblo mocobí. La interacción y la residencia de Paucke durante dieciocho años en las reducciones le permitieron acercarse a este grupo, indagando en facetas que otros agentes coloniales no pudieron, logrando desarrollar una obra sobre las costumbres y modos de vivir de dicha etnia.

${ }^{13}$ Grenón, 1948: 17.
} 
la provincia como profesor de Gramática del colegio de Córdoba, y para el año 1748 en el de Santa Fe.

El P. Canelas llegó al pueblo de los mocobíes a principios del año 1749, se dedicó al aprendizaje de la lengua Mocobí, y a cuidar de la escuela de los muchachos, ejerciendo sus ministerios con los indios.

Con ellos permaneció en forma permanente hasta 1759, porque como refiere Paucke, debió solicitar en 1760 al rector de Santa Fe que le enviara al P. Manuel Canelas (que antes había vivido conmigo en la reducción y entendía bien este idioma) para que lo asistiera en una epidemia de viruelas que se había generado en septiembre de 1759 y duró al menos hasta enero del año siguiente.

Tomó el $4^{\circ}$ voto en esa ciudad el 25-II-1752 y al año siguiente se encontraba ya como cura del pueblo de San Javier de indios Mocobíes, acompañado de Florián Paucke y Domingo Ugarte. En 1763 estaba de regreso en el Colegio de Santa Fe como doctrinero en la matriz. La expulsión lo encontró en el colegio de Córdoba. Falleció en Faenza el 22-III-1773.

\section{Una lectura crítica a la fuente}

El manuscrito original del P. Manuel Canelas se dividió en dos grandes partes que estructuraron su relato. La primera de ellas analiza las particularidades de la nación mocobí ${ }^{14}$ tales como carácter, forma de vida, costumbres, vida natural, alimentación. Mientras que en la segunda parte el análisis se orienta al momento de la conversión a la fe cristiana, a partir de las tareas misionales.

En el I capítulo de la relación, el primer título corresponde al "Oscuro origen de la nación...” en el cual se narra una historia de los propios indígenas sobre la creación del mundo que hace referencia a que "el gran mocobí se valió de una olla de tierra y formadas hembras de varoncitos" se fueron multiplicando y poblando la tierra" ${ }^{\text {" }}$

En este primer relato mitológico, Canelas trata de asociar y vincular a las ideas de la Creación en el Antiguo Testamento pues sostiene la idea de la creación del hombre por Dios en la tierra y luego la creación de Eva de la costilla de Adán. Instala la imagen de que esas historietas, a pesar de que fueron perdiendo la verdad con el paso del tiempo, nos indican que "los mocobíes descendieron de los hebreos o que tuvieron algún comercio con ellos”16.

Canelas trascribe otras historias de la cosmovisión y mitología aunque siempre tiende a vincularlas con la verdad revelada del Antiguo Testamento, por ejemplo,

\footnotetext{
${ }^{14}$ Los mocobíes, parcialidad del Gran Chaco, constituían el grupo lingüístico guaycurú. Su organización social previa a la trasformación producidas por el avance de la colonización, podría sintetizarse como de "las sociedades cazadoras-recolectoras pescadoras semi-nómades, conformadas por base exógena que se desplazaban por territorios establecidos como propios y que se asentaban temporalmente en lugares con abundancia de caza (Citro, 2008).

${ }^{15}$ Archivo Histórico de la Compañía de Jesús. Cataluña. (ARX-HIST. SJ. Catalunya) AC/MI 02. En adelante: Legajo Camaño n 8:Ms. Manuel Canelas fs. 177-347.

${ }^{16}$ Ibíd, f. 177.
} 
cuando los mocobíes detuvieron al sol con sus manos o dardos de una revolución de los cielos, que la denomina ficción se divisa algo de Josué ${ }^{17}$.

Una característica que aparece del pueblo mocobí es la circuncisión, costumbre que se realizaba a los dieciocho años o más, según Canelas. Esta práctica también tenían los hebreos pero era a los ochos días de edad, en tanto los mocobíes mostraban una corrupción o diferencia a la de los primeros, reflexión que realizaba el propio Canelas en su relato.

Este primer capítulo que refleja la cosmovisión y algunas historias de la cultura oral del pueblo mocobí, no fueron trascriptas en la obra de Guillermo Furlong. Indudablemente este último priorizó la descripción de la nación mocobí en torno a la reducción de San Javier, profundizó en la forma de vida, sociabilidad, mundo natural para posteriormente, dar cuenta de los adelantos a través del asentamiento en torno a la reducción y la conversión a la fe. En este sentido, no podía incorporarse la cuestión de la cosmovisión indígena.

Este rico manuscrito fue utilizado parcialmente por Furlong, tomando algunas ricas descripciones de la vida de los mocobí. Es interesante el ensamble que se realiza con las ideas de los otros jesuitas como Paucke y Antonio Bustillo, pero quedan muchos aspectos que no fueron tratados.

\section{El asentamiento, la fauna, el medio natural de la nación Mocobí}

El capítulo II que corresponde a la primera parte de la relación, hace referencia a cuestiones referidas a sus modos de vida, por ejemplo, se analiza su sitio, pueblo y casas.

El relato se inicia con la descripción geográfica del medio en el que habitan los mocobíes, que es la ribera del Río Bermejo o Grande. Este espacio permitió un dominio natural de las aguas y de sus animales, lo que se observa en el conocimiento de toda la fauna entre los que se destacan los dorados o achioaznac, aunque Paucke en su obra Hacia allá y para acá los nombra como aciasnac, "no sin motivo, porque sus escamas son completamente como si estuvieran cubiertas con oro pálido" 18 . También en los ríos se criaban los pacuz- docop, zurubís o en mocobí "achibcaic”, bogas, rayas, sábalos, anguilas, etc.

Esta descripción sobre la fauna del río es muy escueta a diferencia de lo descripto por Paucke en su parte denominada "Descripción del Gran Chaco en Paracuaria”, hasta el propio Furlong sostiene que lo reseñado por Canelas es "harto concisa" 19 .

En relación al río, Canelas comenta las inclemencias de las inundaciones, sus beneficios y perjuicios, que por un lado, deja intransitables las tierras para el avance español hasta las rancherías y por otro, provoca la imposibilidad de la caza. A su vez,

\footnotetext{
${ }^{17}$ La historia de Josué, ayudante de Moisés, hace referencia a una guerra generada entre los jefes amorreos y por otro lado, Josué. Este último pedirá a Javé que detenga el sol sobre Gabaón y la luna sobre el valle de Ayalón. De ese modo, logran proseguir la venganza sobre sus enemigos. Este hecho mitológico en el cual intervienen Yave es comparado con el que narran los mocobíes según Canelas.

${ }^{18}$ Paucke, 1943: 2.

${ }^{19}$ Furlong, 1938: 74.
} 
alude a que las tierras fecundas son muy pocas, por lo que la práctica de siembra no se realiza sino que tratan de aprovechar los productos que brinda la naturaleza.

Al señalar el aprovechamiento de lo natural, se analiza los frutales tales como la algarroba y el chañar, en torno a estas dos especies se hace su economía toda y su única posesión. A diferencia de Canelas, la obra de Paucke nos permite conocer la terminología en lengua mocobí del árbol de algarroba blanca, amapic, y chañar, batacaic, este dedica un capítulo de su obra dando cuenta de las formas de extracción de la fruta, la utilización por parte de españoles e indígenas, y sus elaboraciones posteriores en harina, bebida y chicha.

Estos frutales fueron aprovechados tanto por indígenas como por los propios españoles, lo cual según Canelas, no ofreció recelo alguno aunque se produjo la deslealtad de los españoles que robaron las piruas cuya consecuencia fue el peligro de deshacerse de las reducciones.

Posteriormente comenta brevemente los diferentes árboles y maderas que existen en los bosques tales como quebrachos, espinillo, palo blanco, lapacho, las palmas. Menciona que las cañas sirven para tejer paños como por ejemplo, el de luto que utilizan las viudas. También se dedica a precisar los tipos de abejas y miel que aparecen en los bosques.

Delinea también las características de algunos felinos a los que el autor denomina tigres ${ }^{20}$, y las particularidades que implica la caza por parte de los indígenas quienes bregan con tanta tremenda fiera. Paucke realiza una ilustración sobre la manera de enlazar a los animales en la caza.

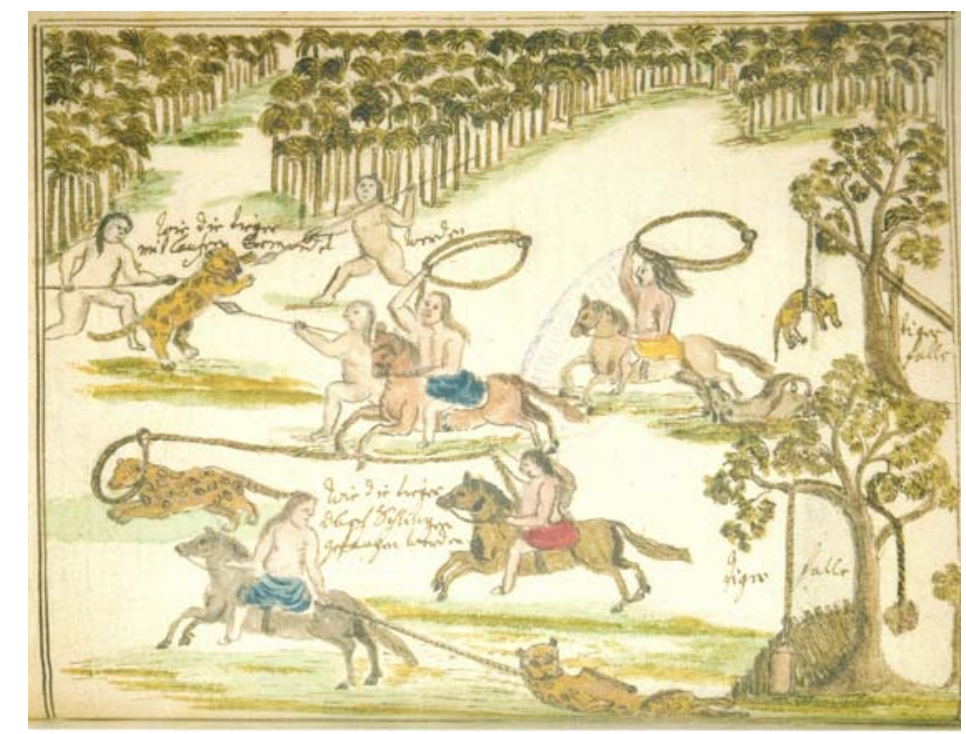

Antes de terminar el capítulo, se hace referencia a la disposición interna de la nación en las rancherías o tolderías, alrededor de una plaza, que sirve para los festejos y desahogos del pueblo.

\footnotetext{
${ }^{20}$ Cuando menciona tigres está refiriéndose a yaguaretés.
} 


\section{Aspectos de la vida cotidiana}

En el capítulo III, analiza la forma de vestir de los mocobíes refutando las ideas de Pedro Lozano que aparecen en la Historia del Gran Chaco, de que andaban desnudos. En relación a esto, sostiene Paucke que "en su tierra salvaje todos anduvieron desnudos en tiempos anteriores pero ahora a causa de la vecindad y el conocimiento de los españoles han tratado asimismo a cubrirse los sitios más secretos..."21. Por eso, creemos que Canelas reflejan una etapa posterior del primitivo pueblo mocobí, en el sentido de que trasmite el proceso de adaptación a costumbres hispánicas que se adoptaron a partir de la instauración de las reducciones. Por eso dirá lo siguiente: "No andan desnudos ni anda desnuda esta nación, bien que dentro de la casa solo se cubren en tiempo de calor, cuanto basta para no estar totalmente indecentes" 22 hasta incluso tienen una ropa de gala, que son las plumas de varios colores, los collares de conchas y pendientes de metal.

Se destaca en esta descripción "las que corren por brujas" ${ }^{23}$ que se identifican por el horror de su aspecto: "esposas propias del diablo engreídas en su propia monstruosidad". Estas son las denominadas hechiceras, temidas por todos y médicos de todas las enfermedades, según Canelas, sus rostros están mugrientos, renegridos, sus vestidos viejos y despedazados.

En cuanto a su comida, Canelas los describe por su voracidad a los alimentos diciendo que a pesar de la reducirlos en el pueblo "nunca los pudimos reducir a que no acabasen en dos o tres días lo que se les daba para toda la semana”. En esa idea de voracidad, también reflejan que estaban acostumbrados a pasar mucho tiempo sin alimento en tiempos de hambres largos con lo cual se asocia a su modo de vida adaptado a la estacionalidad de ciertos recursos y a la escasez de estos.

En relación a su costumbre alimentarias, se vincula la práctica de los ayunos una vez recibida la fe católica, es decir, acostumbrados a pasar varios días sin comer por sus prácticas de caza, se aplicaban a cumplir el ayuno en nombre de nuestro Padre.

Con respecto al alimento, se pueden establecer dos momentos: los que comían antes de la llegada de los españoles y las nuevas costumbres instauradas con la conquista, y realizadas en su reducción.

Su principal alimento era la carne que provenía de algunos felinos (yaguareté), que era más apetecible que la carne de vaca. Refiere Paucke una anécdota con Canelas, en la cual a escondidas de este último asó carne de tigre y este tomó con apetito el asadito sin sospecha alguna que era carne de tigre. Sus palabras fueron "debo confesar sin embargo que me ha gustado muchísimo y he creído comer el mejor carnero"24.

La carne podía ser "cocida al agua "nebolec", asada a las brasas "neoic" o en asador de palo que dicen, Nazeguec" 25 . A diferencia de los españoles, no utilizaban los condimentos ni aún la sal. Posteriormente en la reducción, se fueron acostumbrando al uso de la sal y hasta incluso de un picante, que denominan cumbar. El sustento se reducía a raíces, algarroba, miel, gusanillos o hijuelos hasta langostas.

\footnotetext{
${ }^{21}$ Paucke, 1943: 485.

${ }^{22}$ Legajo Camaño. Ms.Manuel Canelas. f 200.

${ }^{23}$ Ibíd. f. 208.

24 Paucke, 1943: 25.

${ }^{25}$ Legajo Camaño. Ms.Manuel Canelas f. 215.
} 
Una vez en el pueblo, aprendieron a comer pan, pues "el apetito que les entró al pan fue increíble, siendo ellos golosísimos, mostraba gustarle más que la miel” 26. Aprovecharon en un principio la cebada para utilizar la harina, pero "venció su apetito en gran cortedad, y se aplicaron a hacer chacras de trigo y hasta incluso, instaban para que los misioneros hicieran tahonas a fin de satisfacer al grande gusto de comerlo.

En relación a esto, se podría analizar la instauración de la agricultura incipiente en la reducción. Por los indicios en las fuentes podemos señalar que se dio a partir de la tarea del padre Paucke el cual introdujo las tareas de labranza a los mocobíes que intercambiaban su trabajo por yerba. Aunque por lo que refiere Canelas los productos obtenidos de la tierra, no alcanzaron a tener la importancia central para los Mocobíes.

\section{Deidades e Inmortalidad del alma}

Canelas iniciaba el capítulo IV con una frase excepcional: "Socorrido y contento su cuerpo, con que tener que comer y vestir, no tenían más cuidado de sus almas, que el que tienen los brutos de su vida"27. Esta breve descripción caracterizaba la visión del mundo de los mocobíes, los cuales aunque creían que el alma "se iba a otra parte" para lo cual proveían en los sepulcros de víveres para el alma aunque no habían desarrollado una noción más acabada de la inmortalidad del alma, eso permitía a Canelas compararlos con los brutos.

En esa noción de inmortalidad no había rastros de alguna salvación ni de condena pues su forma de vida nómade y salvaje generaba una preocupación por la vida terrenal más que por lo profano. Lo que se justifica en el desconocimiento en la deidad pues según Canelas "no se descubre rastros alguno ni en su uso ni en los vocablos de su lengua rastro alguno de religión" ${ }^{28}$. En tanto Paucke los describe como "paganos que sin conocer a Dios no conciben ninguna fe, ninguna doctrina y ninguna educación moral” ${ }^{29}$, o Canelas como finitos teístas.

En cuanto a la deidad, sostiene Furlong que el jesuita que más conocía sobre eso era el Padre Bustillo el cual sostenía "no hallarse ninguna deidad entre las dos célebres naciones mocobí y abipona a quien prestaran el más mínimo culto, creen que en partida esta vida viven en la otra y en ella ejercen las mismas operaciones que en esta, por lo que acostumbran... a matar los mejores caballos para tener... con que buscar su comida" 30 .

A pesar de no tener deidad, concibe dos nociones que nos permiten una apertura a su cosmovisión. La primera tiene relación a la Creación y es la noción de "In inca abapegogdi” que significa el que nos creó, asociado y vinculado a esa idea, aparece el que nada no puede o en mocobí "ini namalica $n$ jecalanapec" que representa a una idea de omnipotencia.

En cuanto al Demonio, Canelas reproduce numerosas apariciones de este a los mocobíes por ejemplo sostiene que se les "aparecía muchas veces en figura humana,

\footnotetext{
${ }^{26}$ Ibíd. f. 219.

${ }^{27}$ Ibíd. f. 221.

${ }^{28}$ Ibíd. f. 221.

${ }^{29}$ Paucke, 1943, II: 247.

${ }^{30}$ Furlong, 1938: 87.
} 
bien que con diferentes seños y vestiduras peregrinas....". "Unas veces se disfrazaba en amor todo el odio mortal....decíales que era su Creador"31. Pero esto le sirve para justificar que esta nación bárbara no cayó bajo el designio del Demonio sino que el Altísimo Señor pudo sujetarlos.

Canelas refiere que una vez antes de la llegada de los españoles se les apareció Dios montado en una mula previniéndoles el peligro de los hombres de color blanco, que habían de penetrar sin otro fin, que beberles la sangre o esclavizarlos. Pero tampoco creyeron en esto, y cayeron bajo la sujeción de los españoles en la vieja Concepción.

La figura de las brujas era retomada por Canelas, lo que fue tratado con detalle en diferentes escrituras jesuíticas como en la de Martin Dobrizhoffer, Florian Paucke, José Sánchez Labrador y José Jolís debido a que constituía "un enemigo principal en la tarea de evangelización”32. En este caso, se alude a la figura femenina donde la presencia de ésta en el colectivo social era más temida que de los más nobles caciques. Estas buscaban establecer un vínculo constante con el agente del mal y desarrollaban, según la mirada jesuita, todo tipo de engaños al pueblo. Paucke lo definía en términos semejantes sosteniendo que las hechiceras eran engañadoras y a su vez, se beneficiaban recibiendo el pago por los favores que realizaba, lo cual, significaba una buena manta $o$ una vaca o un caballo.

Como en la mayoría de los casos, los jesuitas optan por poner a prueba a los hechiceros en diferentes circunstancias con el fin de revelar a la población las mentiras y falacias de sus creencias. Por lo que en este caso Canelas o Paucke como los demás misioneros persiguen un mecanismo de increpar los poderes y dominios de estos hechiceros frente a la comunidad.

En otro plano, plantea Canelas que durante la primavera se hacen fiestas por la proximidad en la obtención de la fruta, y festejan la aparición de las estrellas en el cielo como la entrada de la primavera.

\section{Usos y costumbres de la nación mocobí}

Canelas al hablar de costumbres y usos de la parcialidad se concentra en el análisis sobre las prácticas familiares y matrimoniales que tenía este pueblo y que según él, fueron perdiendo a partir de la conversión y de la guerra.

La base fundamental que rige su modo de vida es la necesidad de mantener aseguradas las generaciones futuras, es decir, como sostiene Canelas "el innato deseo de la generación a mantener la vida ${ }^{33}$.

El matrimonio era una práctica central en los mocobíes, esta unión estaba precedida por la decisión de los padres de concertar un enlace entre el hijo y la hija desde la niñez, lo que significa que dichos hijos no puedan generar una relación reciproca hasta el casamiento porque preexistía un convenio de voluntades fijado con

\footnotetext{
${ }^{31}$ Legajo Camaño. Ms. Manuel Canelas, f. 224.

${ }^{32}$ Rosso, 2012: 166.

${ }^{33}$ Legajo Camaño. Ms. Manuel Canelas, f.238.
} 
anterioridad. En caso de no existir dicho convenio, "el joven debía dar muestra de valor o de distinguida sangre ${ }^{\text {"34. }}$.

Una vez desarrollado el enlace, el esposo debía otorgar una serie de bienes al padre y a su esposa, que eran regalos ya sea caballos, pieles, panales y animales de caza. En estos regalos se observa cómo definían su economía dedicada al ganado caballar por excelencia, lo que se convertía en un elemento de intercambio, pero a su vez, la práctica revestía otro carácter, pues el matrimonio se convertía en un verdadero contrato, señala el P. Bustillo que interviene "un verdadero contrato natural: compran a la mujer por dos o cuatro caballos, con su silla o lomillas que es el aparejo de aquellas tierras..."35.

También en dicha práctica se pueden problematizar e indagar las particularidades referentes a las distinciones sociales que existían dentro de la comunidad, dicha temática ha sido objeto de numerosos análisis antropológicos y etnográficos entre los cuales se destacan los de Branislava Susnik, James Saeger y Florencia Nesis.

En dicho sentido establece Canelas que los "nobles no se juntaban con consortes de menor graduación y mucho menos con gente plebeya: celando con extremo el decoro de sus familias". En cambio "los indios plebeyos toman fácilmente mujer de otra nación”, por eso los de linaje o "nobles” se distinguen por descender de mocobí, "únicamente sin que se divise en toda su ascendencia sangre extraña”. En estas descripciones a pesar de que se recurren a categorías propias del mundo hispano o europeo, aludiendo a plebeyos, nobles, linaje, cautivos, se observa que existían diferencias sociales que los misioneros percibieron en su convivencia con esta nación indígena.

La idea de diferenciación social también se puede analizar como lo sugiere, Nesis en su obra, pues "tanto los caciques como sus hijos podían tener varias mujeres y esposas, mientras que los demás hombres, si bien tenían algunas concubinas, solamente contraían casamiento con una esposa” ${ }^{36}$. De ahí se daba una desigualdad en el carácter de concubina y esposa, que según Canelas, la primera residía con sus padres en los bosques, mientras que la segunda vivía con su esposo. La relación entre ambas podía ser violenta, hasta incluso se generalizó la práctica de riña en público, estando presente el marido.

El relato de Canelas aborda las distintas etapas de la vida desde la niñez hasta la adultez, reflejando la diferenciación sexual y la formación en los varones en las prácticas de la guerra y sus valores vinculados a esa actividad primordial en la vida. Por ejemplo, "en su infancia si es varón, le ponen en la manecilla un arquito con su flechita, y cuando ya empiezan a andar, la madre cogiéndole las manos se la hace disparar" "37. Ya a los 12 años, tienen gran cuidado las madres y mucho más las abuelas, de que los varones se hieran los brazos para que empiecen a dar muestras de coraje. La formación y educación de los guerreros prosigue en numerosas pruebas que le permiten moldear su carácter y ciertos valores como el coraje y la valentía.

\footnotetext{
${ }^{34}$ Ibíd. f. 243.

${ }^{35}$ Furlong, 1938: 89.

${ }^{36}$ Nesis, 2005: 79.

${ }^{37}$ Legajo Camaño. Ms. Manuel Canelas, ff. 250 -251.
} 
Un elemento que llama la atención en esta parcialidad es que según los misioneros, los niños manejan a su antojo al padre y a la madre. "Los padres no encargan nada al niño, tampoco prohíben nada y los hijos obedecen poco a los padres" 38 . En palabras de Canelas, son los padres los que respetan a los hijos.

\section{La diferenciación sexual y la guerra}

Esta parcialidad del Gran Chaco, dedicada a la caza, recolección y la pesca tenía desarrollada una diferenciación de tareas según el sexo y la edad. Por un lado, en la mujer recaían una serie de tareas familiares y económicas que la convierten en verdaderas esclavas: "ellas han de ir por el agua, por leña, hacer el fuego, cocer, servir la comida”39. A eso se le sumaban las tareas de recolección de frutos, raíces como la algarroba; la caza de animales pequeños, hilar, tejer y pintar en las estaciones de verano. A veces, debían salir al campo por las cabalgadura, han de enlomillar, tener la rienda y dar en el dardo.

Por su parte, los varones se dedicaban a la guerra lo que condicionaba sus ocupaciones y tareas que se vinculaban intrínsecamente con dicha función. En este sentido, esta parcialidad manifestaba una tendencia hacia las guerras interparciales o como definía Canelas, las guerras entre sí, pues la guerra se constituía en una forma de interacción con el otro, ya sea al interior de los propios grupos mocobíes o de otras etnias como abipones, tobas, lules, vilelas y payaguas ${ }^{40}$.

"Los varones pasan la mayor parte de su vida en la suma ociosidad, vagueando de rancho en rancho" 41 , aunque tenían alguna ocupación, una de esas era hacer las armas. Entre las armas que fabricaban se destacan los dardos, las macanas y arcos de flecha, para lo cual debían desarrollar la destreza en el manejo de dichas armas. Su segunda ocupación era la caza como mecanismo de aprovisionamiento de los alimentos, y la tercera era la guerra en la cual reflejan su espíritu guerrero. Según Canelas, hacen la guerra por la traición, no por el común de guerrear principalmente con el español.

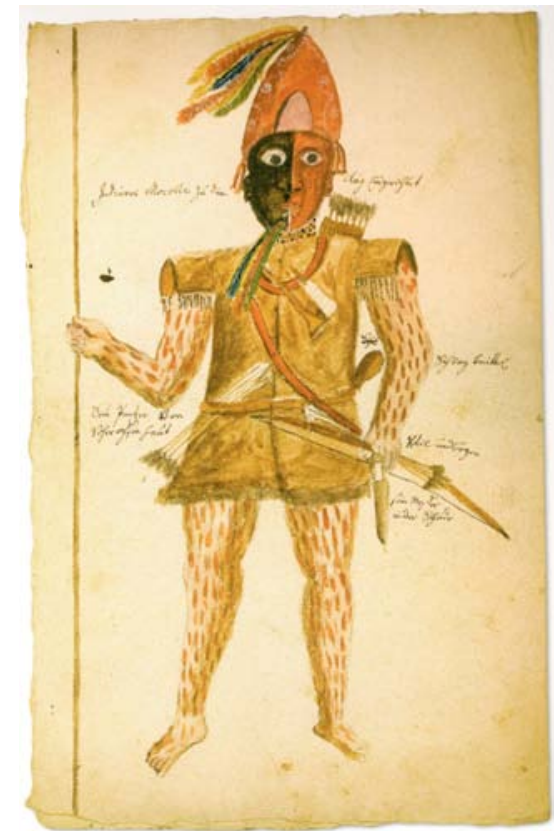

Uno de los objetivos de la guerra, es realizar los asaltos y el denominado "pillaje" a las poblaciones donde desarrollan diversas tareas de espionajes anteriores a la acometida, quizás el interés, es lograr el mayor provecho y éxito en dicha tarea. La actividad es precedida por un verdadero festín, pues "hacen su chicha, se pintan con manchas

\footnotetext{
${ }^{38}$ Paucke, 1943, II: 243.

${ }^{39}$ Legajo Camaño. Ms. Manuel Canelas, f. 255.

${ }^{40}$ Perusset-Rosso, 2009: 69; Vitar, 2015: 14 y Salinas, 2009: 293-322.

${ }^{41}$ Legajo Camaño. Ms. Manuel Canelas, f 257.
} 
negras y coloradas, los rostros, los brazos, deparándose tantos otros monstruos del infierno" $"$.

En la guerra también es posible analizar el fenómeno de los liderazgos indígenas y diferenciaciones sociales dentro de la parcialidad. Por ejemplo, sostiene Canelas que es el cacique principal el que encabeza las filas, seguido por sus hermanos y parientes, luego otra parentela y así van alargando las filas según las familias. Además no sólo significaba encabezar la guerra, sino que en el cacique recaía la tarea de inspirar la valentía, y los razonamientos para movilizar al resto de los hombres. Mientras que Paucke explicaba que era el cacique quien podía invitar a cometer un robo o a pelear contra otros.

La guerra implica una celebración una vez acabada, en la cual interviene la comunidad o grupo entero, principalmente se destacan las Brujas y Viejas que procedían con cánticos alabando a los vencidos y llorando por los vencedores. Una de las manifestaciones era elevar las cabezas en la punta de los dardos, como símbolo de trofeo. De esa forma, "los vencedores se apropiaban de la vida-nombre del enemigo y creían tener el pleno derecho de usarlo como un poder" ${ }^{\text {"43 }}$.

De esa forma, los mocobíes utilizan a la guerra como una forma de demostración de valentía, valor y coraje en la comunidad, lo que se puede corroborar por ejemplo, "los que mataron tienen a gran gloria de servirse de ellos como de mates en que beben..."44, en cambio, los que salieron heridos de la batalla, entran al pueblo melancólicos, recogidos en sus ranchos... por avergonzarse en público del hecho.

\section{La borrachera, sus juegos, enfermedades, muertes y entierros}

Los jesuitas en general, han desarrollado gran interés sobre las fiestas o ceremonias de bebida de las poblaciones indígenas, por lo cual han dedicado siempre en sus escritos páginas exclusivas para narrar e ilustrar prácticas asociadas con la bebida y su consumo. Paucke en su conocida obra, dedicó dos capítulos sobre esta temática, en el apartado denominado "El indio borracho" y el de "Ceremonias durante la borrachera".

Por su parte, Canelas realiza una crítica peyorativa cuando inicia su capítulo sosteniendo que una ocupación de los mocobíes era la borrachera, por el tiempo en que se toman y dedican a la misma. Busca desarrollar una explicación sobre esta práctica, aunque manifiesta misterios y falta de comprensión frente a esta denominada “inclinación”.

El consumo de la bebida al igual que la guerra, se convierte en una actividad que ejercen los varones primordialmente, pues son raras las mujeres que beben, pero también es una forma de relacionarse con otros pueblos y hasta compartir dicha celebración. En torno a la bebida, se realizan numerosas fiestas o ceremonias en las cuales para beberlas se sientan alrededor del noque o puestos en círculos, en donde las chinas se la van sirviendo. Estas fiestas se realizan en una etapa del año, que es en la primavera cuando las mujeres juntan la miel y hacen la bebida; lo cual se extiende según Canelas, hasta lo que dura la miel y algarroba.

\footnotetext{
${ }^{42}$ Ibíd. f. 272.

${ }^{43}$ Perusset y Rosso. 2009: 71.

${ }^{44}$ Legajo Camaño. Ms. Manuel Canelas, f .283.
} 
Las borracheras generaron numerosos efectos, que fueron visibilizados por los misioneros, Canelas sostendrá que "cuando empiezan a calentarse, comienzan a zaherirse con picantes dichos... se hieren unos a otros sensiblemente... se matan como perros" 45 . Paucke los describe como "animales salvajes, indómitos e iracundos, hasta mulares y burros que no tienen entendimiento alguno" ${ }^{\text {"6 }}$.

Pero a su vez, percibían los cambios de humor y estado de ánimo que afectaban a los mocobíes en situaciones de borrachera, como la diversidad de afectos con que quedan, unos tristes, otros en gran silencio, otros llorando, otros dando alaridos, otros cantando, otros alegres.

Canelas en su descripción sobre la ociosidad de la parcialidad, generaba un breve análisis y descripción sobre las formas de juegos y divertimentos que tenía este pueblo, sobresaliendo el característico duelo o pelea; además de las corridas de caballos apostando algo de sus pocos haberes, y los juegos de pelota. Aunque como se caracteriza al inicio de la descripción, son reducidos los esparcimientos que se relacionan con el mundo natural que los rodea, el bosque, y además mantienen estrecha vinculación con las prácticas centrales de la parcialidad, en especial, con la caza por ese motivo adquiere importancia las recreaciones con el caballo y los dardos.

Por otra parte, en la relación se dedica un apartado para referir a la salud y enfermedades de la parcialidad adquiriendo relevancia en el relato "las pestes y viruelas que hicieron estrago en las rancherías" 47 que según otras fuentes jesuíticas estas azotaron a la reducción de San Javier entre los años de 1745, 1759, 1760. Aunque en la obra de Canelas se ignoran las causas de estas enfermedades endémicas se sostiene que los efectos fueron mayores a la disminución que habían generado las guerras habidas entre sí y con el español.

La peste también fue abordada por Paucke en un capítulo de su obra denominado "De la peste india o viruela” en el cual sostiene que “cuando las viruelas penetran entre los indios salvajes es algo tan lastimoso como en nuestros países..." y la única manera de accionar frente a la peste es huir hacia los montes, "abandonan a su enfermo y sus tolderías pero no son ellos tan olvidadizos ni descuidados para con el virulento que no pongan antes a su lado una gran vasija con agua y carne asada y frutas del monte..."48.

En cuanto a la problemática de los médicos y curas para las enfermedades, como señalamos anteriormente, era común la existencia de brujos y brujas en la comunidad, lo cual era objeto de críticas por parte de los misiones en general, y en particular, Canelas sostendrá "que con embustes, engaños y amenazas, más que con medicinas, logran toda aceptación y respeto" ${ }^{49}$. Este aspecto revela uno de los puntos más conflictivos con las practicas indígenas que debían transformarse a partir de la evangelización, pues el control sobre las concepciones y las prácticas relacionadas con sus creencias representaban espacios claves donde los sacerdotes competían con los chamanes.

En relación a las enfermedades, se alude a la muerte como una situación causada por la inspiración de alguien o influencia ajena, a tal punto que Canelas sostiene que

\footnotetext{
${ }^{45}$ Ibíd. f. 285.

${ }^{46}$ Paucke, II: 199.

${ }^{47}$ Legajo Camaño. Ms.Manuel Canelas .292.

${ }^{48}$ Paucke, 1943, III: 29.

${ }^{49}$ Legajo Camaño. Ms. Manuel Canelas, f. 293.
} 
"cuando moría una persona principal, peligraban los brujos y brujas porque si entraba en sospecha que ellos causaron la muerte, la pagaban con la vida" ${ }^{50}$. Esta capacidad de matar del chamán o brujo era observada ya por Paucke y en Dobrizhoffer, por lo que estos "eran temidos por el resto de la sociedad" 51 .

Las ceremonias posteriores a la muerte eran los entierros acompañados por distintas demostraciones de llanto y confusión que era una costumbre en esta etnia. En tanto, "la sepultura se realizaba siempre fuera del pueblo a distancia por lo común de una o dos millas". El duelo era más visible en las viudas, Canelas lo juzgaba como “excesivos llantos gobernados por razón de estado", quizás en esta frase se refleje el lugar primordial del hombre en una sociedad guerrera en la cual el hombre-esposo ejercía una presión en las mujeres sujetas a ellos. Este duelo duraba hasta la muerte o hasta producirse nuevas nupcias.

\section{De los genios u otras calidades de esta nación}

En el capítulo que refiere al genio y calidades de esta nación, encontramos una compleja descripción etnográfica y antropológica sobre la parcialidad. La nación mocobí presenta por un lado su espíritu belicoso pero su genio es suave y dócil como lo define Canelas con lo cual se presenta una notable contradicción, que refleja una mirada construida a partir de sus largos años de convivencia en la reducción con estos. Pues el espíritu belicoso es preclaro ejemplo de sus luchas hacia el exterior y su vida como pueblo cazador-recolector mientras que internamente manifiestan ser pacíficos, fieles en el cumplimiento de la palabra, nada enojadizos y hasta ocultar sus sentimientos.

También son descriptos como verdaderamente despiertos y de genios más alegres, que otras naciones. La crítica surge ligada a la flojedad de la nación, es decir, por la falta de ganas de trabajar para producir el sustento y alimento y abandonar la vida bárbara, esta visión era común en los misioneros aunque Canelas señala que “cuando viene ganas de emprender alguna cosa, son activos, agiles y hábiles para ponerla en ejecución" 52 con lo cual demostraba que existían condiciones físicas, intelectuales y hasta emocionales para poder emprender las tareas. El problema se manifestaba en que no existía una necesidad para generar un cambio de mentalidad y costumbre en esta nación, que siempre se asociaban a la ociosidad.

\section{Una relación de los Mocobíes}

La relación de Manuel Canelas destina el último capítulo para abordar los cambios surgidos en los mocobíes a partir del surgimiento de la reducción, por lo cual denomina a este capítulo "Del principio de la conversión de la Nación Amocobit" denominación que utilizaban los propios indígenas como sostenía Paucke pero los españoles les daban el nombre de mocobíes aunque también usaban el nombre de Guaicurru.

Teniendo en cuenta un contexto general, "los mocobíes hacia inicios del siglo XVIII se movilizaron hacia la región occidental del Chaco, entre el río Pilcomayo y

\footnotetext{
${ }^{50}$ Ibíd. f. 295.

${ }^{51}$ Rosso, 2011: 1-28.

${ }^{52}$ Legajo Camaño. Ms. Manuel Canelas, f. 303.
} 
Bermejo"53. Este desplazamiento no fue accidental sino que surgió a consecuencia de expediciones militares que habían encabezado los españoles a la región, algunas eran encabezadas por el general Urizar y Arespacochaga. Esto genero el asentamiento de los mocobíes sobre las áreas de influencia de Santa Fe y Asunción.

Según la relación de Canelas, la guerra fue el origen más remoto de la conversión a la fe de la nación amocobit, lo que posteriormente implicó la instalación de la reducción de San Javier, surgida a partir de la paz con la nación abipona, la ciudad de Santa Fe de la Vera Cruz, la gobernación de Buenos Aires y la ciudad de Córdoba del Tucumán.

Como se menciona en la relación, la creación de la reducción de San Javier surgió como consecuencia de un largo proceso de negociación, que involucró al gobernador de Santa Fe Echagüe y Andía, con sus tratativas de paces en 1734 y que llevo casi 9 años la negociación. Por otra parte, en este acuerdo intervinieron los caciques principales de la nación como Ariacaiquín, Chiatalin, Aletín.

En la versión que elabora Canelas, se sostiene que a los indígenas los movía un interés para asentarse en la reducción, que era el deseo de comer carne y que no tenían otro motivo alguno. Desde la historiografía se sostiene que las reducciones o pueblos significaban para la parcialidad un seguro económico para resolver problemáticas.

Por otra parte, se observa que Canelas busca dar cuenta de las dificultades y privaciones que mantenían los padres en la nueva reducción, lo cual demostraba su gran celo apostólico y entrega. Manifestaba que el futuro de la reducción dependía de la providencia divina pues dirá "que solo Dios... pudo con especiales providencias conservarlo y conducirlo al estado feliz a que llegó" 54 . También se evidencia un interés por elevar la obra misional que encabeza la Compañía de Jesús y sus misioneros en el Gran Chaco que según este exponen a las incomodidades de la vida y oportunidades de muerte solo por la Gloria de Dios con el fin de convertir a dicha parcialidad y otras naciones bárbaras.

Los inicios de la reducción eran descriptos con pocas familias a cargo de un cacique, que poco a poco, fueron recibiendo otros con sus familias y tolderías que llegaron a ser 800 almas y luego mil. Aunque como refleja Canelas, se desarrolló un problema en torno al aprovisionamiento de los recursos, pues había que mantener a tanta gente y procurar en los principios, que no abandonaran el pueblo.

Los socorros económicos y financieros llegaron pocas veces, siendo insuficientes para todas las necesidades de la reducción, por un lado, llegaron de la ciudad de Santa Fe que eran 500 pesos, sumado a la concesión voluntaria proveniente del Sínodo para los misioneros que era unos $200^{55}$. Con el paso de los años, se acrecentó la llegada de provisiones desde Santa Fe dado que se generó una estabilidad económica surgida por la paz de ese modo pasado los 7 años de fundado el pueblo llegaron 9 mil pesos y hasta llego a 14 o 16 mil.

\footnotetext{
${ }^{53}$ Nesis, 2005: 14.

${ }^{54}$ Legajo Camaño. Ms. Manuel Canelas, f. 321.

${ }^{55}$ En este aspecto, Canelas critica duramente a los codiciosos jesuitas que redujeron de 900 a 200 pesos la concesión voluntaria del Sínodo que asigna su Majestad. Esto obligó a que los padres en la reducción vivieran rotos y mal comidos, para llevar adelante la vida en el lugar.
} 
Canelas plantea que la reducción necesitaba desarrollar una actividad económica rentable, para no estar siempre esperando recibir socorros externos, sino más bien, formar una estancia, aunque esto significaba gastar dinero en la compra de cabezas de ganado. En tanto, la estancia debía funcionar por un lado, como aprovisionamiento de alimento para los indígenas y por otro, para resarcir la deuda. Los riesgos eran, "la temida inconstancia de los indios y las más temidas invasiones de los enemigos" "56, además que se recurrió a capataces y peones para que la cuidase. En esta gran dicotomía surgió la estancia de los Calchines sobre un brazo del Paraná, a cuidado de un capataz español, pocos peones asalariados y algunos indios de los reducidos.

La obra de Canelas parece inconclusa ya que no culmina el análisis en alguna idea central ni siquiera manifiesta un interés en comentar la expulsión de los misioneros de San Javier. Tampoco incluye aspectos referentes al pueblo durante la etapa misional, sólo da cuenta de las dificultades experimentadas en el autoabastecimiento y las penurias consecuentes.

Tal vez la dificultad se asienta en la falta de datos que le impiden realizar un mayor tratamiento de la problemática, esto se justifica en los sucesos acontecidos en la expulsión y su abandono de las tierras hispanas despojados de todo documento u otro elemento que no pudieron llevar consigo.

\section{Algunas ideas para concluir}

Esta aproximación al manuscrito de Canelas nos ha servido de marco para analizar en forma general la historiografía jesuítica de la expulsión, que ofrece una mirada etnográfica, antropológica, naturalista de los territorios y poblaciones americanas hacia fines del siglo XVIII, inspirados en los avances de la Ilustración.

Por otra parte, nos ha servido para poner en discusión algunas de las temáticas tratadas por el P. Manuel Canelas centrándonos en aspectos fundamentales para conocer a los mocobíes, grupo perteneciente a los guaycurúes. Creemos que esta fuente contribuye al conocimiento de la parcialidad en cuanto a sus costumbres y formas de vida previa a la llegada de los misioneros. Además, su lectura puede ser complementada con otras narrativas jesuíticas del período para encontrar una versión más acabada de los mocobíes.

Aunque la prosa y la información brindada por Canelas no alcanzan a cubrir una visión total de la parcialidad, aporta aspectos poco tratados en la obra de Florián Paucke. Por otra parte, el análisis nos permitió dar una visión global del manuscrito que no había sido utilizado en su totalidad en anteriores trabajos historiográficos. Esta circunstancia nos permite reforzar las premisas de que es necesario retomar los análisis históricos sobre las fuentes de primera mano, pues la obra de Entre los mocobíes de Furlong no da cuenta de la mirada de Canelas sino que produce un relato propio tomando diferentes ideas de los misioneros.

\footnotetext{
${ }^{56}$ Legajo Camaño. Ms. Manuel Canelas, f. 332.
} 
ANEXO

Divisiones de la relación de $M$. Canelas

\begin{tabular}{|c|c|c|c|}
\hline LIBROS & Capítulos & Título & $\begin{array}{l}\text { Hacia allá y para } \\
\text { acá- Paucke }\end{array}$ \\
\hline \multirow[t]{8}{*}{ PRIMERO } & I & $\begin{array}{l}\text { Oscuro origen de la Nación } \\
\text { Mocobi }\end{array}$ & \\
\hline & II & Su sitio, pueblos y casas & \\
\hline & III & $\begin{array}{c}\text { Su Vestir/ } \\
\text { Su vestir de gala/ } \\
\text { Su comida/ } \\
\text { Sus alimentos }\end{array}$ & \\
\hline & IV & $\begin{array}{l}\text { Su destreza en manejar las } \\
\text { armas }\end{array}$ & \\
\hline & $\begin{array}{l}\text { De sus borracheras, } \\
\text { juegos, enfermedades, } \\
\text { muertes y entierros }\end{array}$ & $\begin{array}{c}\text { Juegos y divertimentos } \\
\text { De salud y enfermedades } \\
\text { De médicos y curas } \\
\text { De muerte y entierros }\end{array}$ & $\begin{array}{l}\text { De la superstición de } \\
\text { los Mocobíes } \\
\text { De la peste india o } \\
\text { viruela }\end{array}$ \\
\hline & $\begin{array}{c}\text { De los genios u otras } \\
\text { calidades de esta } \\
\text { nación }\end{array}$ & & $\begin{array}{c}\text { De los usos del } \\
\text { casamiento y el } \\
\text { matrimonio de los } \\
\text { indios } \\
\text { Cap. XI }\end{array}$ \\
\hline & $\begin{array}{c}\text { Condiciones } \\
\text { peculiares de las } \\
\text { Indias }\end{array}$ & & \\
\hline & $\begin{array}{c}\text { Del juicio, que } \\
\text { formaban del cielo y } \\
\text { sus astros }\end{array}$ & & \\
\hline SEGUNDO & $\begin{array}{l}\text { Del principio de la } \\
\text { conversión de la } \\
\text { Nación Amocobit, y } \\
\text { establecimiento en } \\
\text { pueblo }\end{array}$ & & \\
\hline
\end{tabular}

Elaboración propia. Fuente: Legajo Camaño. Ms.Manuel Canelas. Paucke, Florian, 1943. 


\section{Bibliografía}

Braunstein, José; Salceda, Susana; Calandra, Horacio (2002), Historia de los chaqueños. Buscando en la papelera del reciclaje de la antropología sudamericana. Acata Americana 10, Uppsala.

Citro, Silvia (2008), "Las estéticas del poder entre los mocobí santafesinos”. En: Braunstein, José y Meichtry, Norma. Liderazgo, representatividad y control social en el Gran Chaco. UNNE: Editorial Universitaria de la Universidad Nacional del Nordeste.

(2003) "Hacia una historia del pueblo Mocobí” (Chaco Austral, 16001935) En: Proyecto Lenguas en Peligro en Argentina, Buenos Aires: Facultad de Filosofía y Letras de Buenos Aires. Max Planck Institute. Archivo Dobes.

González, Galaxis Borja (2012), "Las narrativas misioneras y la emergencia de una conciencia -mundo en los impresos jesuíticos alemanes en el siglo XVIII”. Procesos. Revista Ecuatoriana de Historia, II Semestre, Quito.

Furlong SJ, Guillermo (1938), Entre los Mocobíes de Santa Fe, Buenos Airess: Sebastián de Amorrotu e hijos.

Grenón SJ, Pedro (1948), Catálogo de los primeros alumnos del Monserrat, Córdoba: Universidad Nacional de Córdoba.

Nesis, Florencia (2005), Los grupos mocobí en el siglo XVIII, Buenos Aires: Sociedad de Antropología..

O' Neill SJ, Charles y Domínguez SJ, María (2001), Diccionario Histórico de la Compañía de Jesús, Madrid: Universidad Pontificia Comillas.

Page, Carlos A. (2011), "La dispersión de los documentos jesuíticos del Paraguay y los fondo reunidos en los archivos españoles del Instituto". Actas del IX Congreso Argentino de Archivística. 7, 8 y 9 de setiembre de 2011, Resistencia, Chaco, Argentina.

(2012), Las otras reducciones jesuíticas. Emplazamiento territorial, desarrollo urbano y arquitectónico entre los siglos XVII y XVIII, Madrid/Berlin: Editorial Académica Española.

Paucke SJ, Florián (1943), Hacia allá y para acá. Una estancia entre los mocobíes, 1749-1767, Trad. Edmundo Wernicke, Tucumán/Buenos Aires: Universidad Nacional de Tucumán.

Perusset, Macarena y Rosso, Cintia (2009), “Guerra, canibalismo y venganza colonial: los casos mocobí y guaraní”, Memoria Americana, N 17-1. Buenos Aires.

Rosso, Cintia (2012), "Los hechiceros guaycurúes en el Gran Chaco durante el siglo XVIII”, Maguaré. Vol. 26 Nº1. Enero-Junio, Bogotá: Universidad Nacional de Colombia. Bogotá.

(2011), "Epidemias de viruela en las reducciones chaqueñas de abipones y mocobíes durante el siglo XVIII”. EÄ. Vol. 2, ํ⒊

Salinas, María Laura (2009), “San Fernando del Río Negro. Una tentativa evangelizadora jesuítica entre los abipones”, Diálogos, Vol 13, №2, Brasil: Universidad Estadual de Maringá. 
Susnik, Branislava (1969), El indio Colonial en Paraguay. El Chaqueño: Guaycurúes y Chanés Arawak III, Asunción: Museo Etnográfico Andrés Barbero.

Wilde, Guillermo (2013), “Fuentes indígenas en la Sudamérica colonial y republicana: escritura, poder y memoria Escritura, poder y memoria.1a. parte. Vol 3 No1. Corpus. Archivos virtuales de la alteridad americana. http://ppct.caicyt.gov.ar/index.php/corpus/article/view/2823

(2014), "Fuentes indígenas en la Sudamérica colonial y republicana: escritura, poder y memoria. Parte 2 Corpus [En línea], Vol 4, No 1 |, Publicado el 30 junio 2014, consultado el 10 de octubre de 2015. URL: http://corpusarchivos.revues.org/641; DOI : 10.4000/corpusarchivos.641

Vitar, Beatriz (2015), “La subversión del orden Jesuítico. Las ancianas indígenas y su resistencia a la acción misionera en el Chaco”. Revista Missoes. Revista de Ciencias Humanas y Sociales, Brasil: Universidad Federal do Pampa, Vol 1. $\mathrm{N}^{\mathrm{0}} 1$. 